\title{
Diversification of energy supply to the agricultural sector in the conditions of Uzbekistan
}

\author{
Abdujolol Bokiev ${ }^{1 *}$, Nodira Nuralieva ${ }^{1}$, Sanjarbek Sultonov ${ }^{2}$, Abror Botirov ${ }^{1}$, and Urolboy \\ Kholiknazarov ${ }^{1}$ \\ ${ }^{1}$ Tashkent Institute of Irrigation and Agricultural Mechanization Engineers, Tashkent, Uzbekistan \\ ${ }^{2}$ Namangan Institute of Engineering and Technology, Namangan, Uzbekistan
}

\begin{abstract}
At present, the power supply system of the agricultural sector consists only of centralized networks. There are no autonomous-stationary and mobile methods of supply. The current situation of energy consumption in horticulture, such as Beruni district, Karakalpakstan, and further diversification, is analyzed. A systematic approach is applied to the analysis of electrical installations and energy use during agricultural processes, and the corresponding calculation and analytical methods are used to ensure sufficient reliability of the results obtained. The energy balance is compiled in the context of agrotechnical and production processes in fruit and vegetable growing. The issues of central, local, and mobile power supply are studied based on the corresponding energy balance and schedules of electricity consumption. Economic experiments were carried out on a prototype of a mobile power plant "Sun-Wind," with a capacity of $4.5-4.7 \mathrm{~kW} \cdot \mathrm{h}$ (in the daytime), $0.8-1.0 \mathrm{~kW} \cdot \mathrm{h}$ (in the evening). Based on the results obtained, the current and prospective ratios of all three power supply methods are justified. Based on the research results, a system of diversified electricity supply for fruit and vegetable farms was developed and proposed.
\end{abstract}

\section{Introduction}

A significant obstacle to the effective development of the agricultural sector in the conditions of Uzbekistan is the issues of diversification of electricity supply and energy availability of farms. Also relevant is the transfer of agricultural machinery from fossil fuel to electric traction with the use of renewable sources of energy. The reason for this is the following existing problems:

- In the field, due to the absence or remoteness from power supply systems, fertile land is being withdrawn from circulation;

- In animal husbandry, there is an acute shortage of water resources in remote pastures;

- In remote regions, agricultural machinery is often idle due to a lack of fuel and lubricants. As a result, sowing operations are carried out late or manually, and plant processing is not carried out sufficiently $[9,11]$.

* Corresponding author: abdujolol@mail.ru 
In modern farms of the agricultural sector, many different high-efficiency electrical equipment is used. In particular, such as pumping equipment, drip irrigation systems, various lines for processing agricultural products, vegetable storage, etc.

Due to insufficient and unavailability of energy (renewable) produced annually by specialized farms in melon cultivation, horticulture and viticulture, more than $30 \%$ (481.5 thousand tons)does not reach the consumer [10].

Without a high-quality and guaranteed power supply, the efficiency of operation of such lines and equipment is significantly reduced.

When building power supply systems for rural consumers that contain several sources of power supply, as well as operating in a mixed or parallel mode with external power networks, it is necessary to solve several problems related to the management of technological modes of operation not only of distributed generation facilities but also of the distribution network as a whole. These problems can be successfully solved by building promising electric distribution networks using technologies of intelligent electric power systems with an active-adaptive network, in other words, "SmartGrid" technologies [1].

According to WADE (World Alliance for Decentralized Energy), since 2001, the amount of energy produced by decentralized energy sources (DEES) in the world has increased by $3 \%$, accounting for $10 \%$ of the global total. One of the most promising directions for improving the energy efficiency of local power supply systems is the use of renewable energy sources in the energy balance of the regions and the optimization of the operating modes of the main power equipment [2].

Improving the efficiency of electric power generation of autonomous solar stations for power supply to agricultural consumers by justifying the spatial orientation of photo panels based on a comprehensive account of time, geographical, climatic factors, technical and design parameters of the installation is considered in the dissertation work of A.T. Akhmetshin [3].

Installations based on renewable energy sources are the most promising at the moment for autonomous power supply. The combined use of renewable energy sources is the most rational since it has some advantages over single-use. For example, solar and wind energy usually complement each other, making it possible to use installations as part of a hybrid system with significantly lower capacity, and, consequently, lower costs [4].

At present, producers of fruit products are engaged in growth and processing products on the ground, which leads to an increase in the number and types of electrical installations. As a result, the amount of power consumed in the field increases. The main share of energy resources consumed in recent years is electric energy and petroleum products Figure 1.

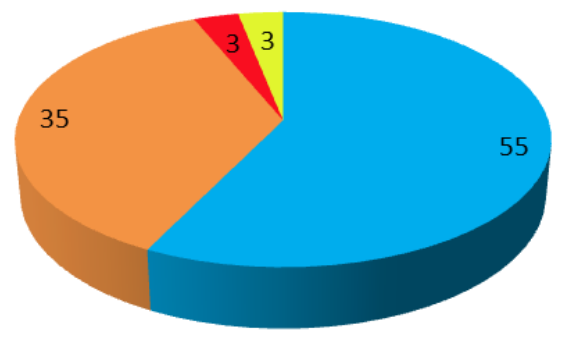

- Electrical energy

- oil product

- heating energy

Natural gas

Fig. 1. Types of energy resources used in fruit and vegetable growing in 2018 (on the example of the object under study), $\%$ 
The purpose of the research is to analyze the system of monopolistic centralized power supply and schedules of electricity consumption in the agricultural sector, to develop a system of the diversified power supply based on renewable energy sources using autonomous stationary and mobile power plants.

\section{Materials and Methods}

The theoretical and methodological basis of the study is the results of the work of scientists on the problems of generating and transmitting electricity for the needs of the agricultural sector. A systematic approach is applied to the analysis of the operation of electrical installations and energy use during various agricultural processes.

During the experiments, the corresponding computational-analytical regression methods were used to ensure the results' sufficient reliability.

Experiments and analysis of the state of electricity supply in the agricultural sector were carried out on the example of the Beruniy district of the Republic of Karakalpakstan.

It is known that agricultural consumers of electric energy have specific modes of operation, mainly depending on agrotechnical requirements and seasonality. Therefore, we introduce the so-called simultaneity coefficient $\mathrm{K}$, which determines the dependence of the calculated values of loads of several consumers on the values of their maximum loads.

Considering that the system of machines and equipment does not work simultaneously in the processes of harvesting and processing agricultural products when calculating loads in the power supply, the arithmetic mean sum of the power values of simultaneously operating equipment is taken multiplied by $\mathrm{K}<1$. In addition, the calculations must take into account the seasonality of the work. For this reason, we use the values of the season given in the table-1.

Table-1. The value of the coefficient of seasonality of consumers of electric energy in agriculture

\begin{tabular}{|c|c|c|c|c|}
\hline \multirow{2}{*}{ Types of consumption } & \multicolumn{4}{|c|}{ Seasons } \\
\cline { 2 - 5 } & Winter & Spring & Winter & Spring \\
\hline Ordinary consumers & 1.0 & 0.8 & 0.7 & 0.9 \\
\hline Irrigation & $0-0.1$ & $0.3-0.5$ & 1.0 & $0.2-0.5$ \\
\hline Electric heating in the closed ground & 0.3 & 1.0 & 0 & 0 \\
\hline Autumn-winter consumers & 0.2 & 0 & 1.0 & 1.0 \\
\hline
\end{tabular}

The diagram analysis shows that the total consumption of electric energy in agriculture (taking into account the population but excluding pumping stations) of the total consumption is $7.5 \%$. This indicator is considered low from the point of view of the current electrical technologies level. It is necessary to provide them with high-quality and guaranteed energy for a wide distribution of various modern energy-efficient technologies on remote farms.

Daily and monthly indicators of energy consumption of fruit and vegetable farms in the processes of cultivation, harvesting, processing, and storage by sector are used to construct daily and annual schedules of loads. Based on the variety of plants and agrotechnical requirements, we will calculate electric energy consumption during the irrigation, processing, and storage of agricultural products. Information on the volume of sales of grown products in fresh form, after processing, and after the storage is obtained from the static reports of the district and entered in the 2-table. 
Table-2. Indicators of energy consumption of fruit and vegetable farms in the processes of cultivation, harvesting, processing, and storage by sectors of the Beruniy district

\begin{tabular}{|c|c|c|c|c|c|c|c|}
\hline \multirow{2}{*}{$\begin{array}{l}\text { Sector } \\
\text { No. }\end{array}$} & \multirow{2}{*}{$\begin{array}{l}\text { The } \\
\text { acreage of } \\
\text { crops } \\
\text { (hectares) }\end{array}$} & \multirow[b]{2}{*}{ Irrigation } & \multicolumn{2}{|c|}{ Recycling } & \multicolumn{2}{|c|}{ Storage } & \multirow{2}{*}{$\begin{array}{c}\text { Total } \\
\text { capacity } \\
\text { by sector } \\
\\
\mathrm{kW}^{*} \mathrm{~h}\end{array}$} \\
\hline & & & $\begin{array}{l}\text { crop area } \\
\text { (hectares) }\end{array}$ & $\mathrm{kW} * \mathrm{~h}$ & $\begin{array}{c}\text { crop } \\
\text { area } \\
\text { (hecta } \\
\text { res) }\end{array}$ & $\mathrm{kW} * \mathrm{~h}$ & \\
\hline 1 & $21(8)^{*}$ & 10625 & 16 & 11858 & 12 & 79200 & 101683 \\
\hline 2 & $27(9)^{*}$ & 13750 & 14 & 9438 & 14 & 86400 & 109588 \\
\hline 3 & $34(10)^{*}$ & 16875 & 20 & 14520 & 10 & 72000 & 103395 \\
\hline 4 & $60(22)^{*}$ & 30000 & 12 & 8954 & 7 & 57600 & 96554 \\
\hline 5 & $65(21)^{*}$ & 33125 & 10 & 7502 & 9 & 72000 & 112627 \\
\hline 6 & $73(20)^{*}$ & 35625 & 8 & 5808 & 8 & 64800 & 106233 \\
\hline in total & $280(90)^{*}$ & 140000 & 80 & 58080 & 60 & 432000 & 630080 \\
\hline
\end{tabular}

Notes - *-gardens.

The power supply of all agricultural facilities in the district depends on centralized lines. This, in turn, negatively affects the widespread introduction of modern energy-efficient lines on remote farms. The structure of electricity supply to agricultural facilities of the Beruniy district for 2017 is shown in Figure 2.

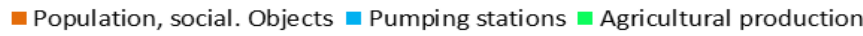

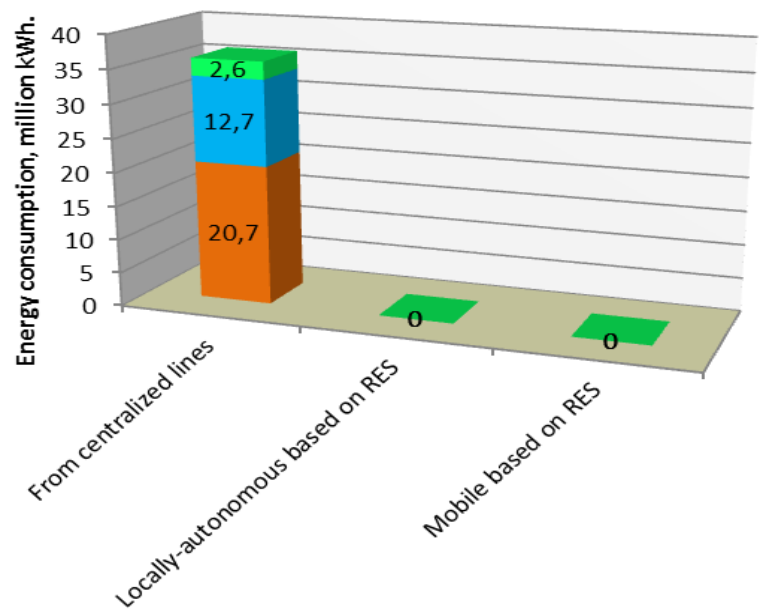

Fig. 2. Structure of electricity supply to agricultural facilities of Beruniysky district for 2019

\section{Results and Discussions}

As you know, consumers in remote regions consist of equipment with low energy performance, located at fairly remote distances from each other, the schedules of their loading in the conditions of power supply are seasonal. The power density of consumers in remote regions per 1 hectare of the area is on average no more than $10 \mathrm{~kW}$ of power. According to this, with a centralized method of power supply, more than $75 \%$ of the costs 
are for the construction of distribution networks of $0.4-10 \mathrm{kV}$ [12]. Therefore, from an economic and technological point of view, a centralized method of energy supply for remote regions can, in some cases, be considered inefficient. This is justified by the following reasons:

- Relatively low consumer energy density;

- Dependence on the season of electricity consumption modes;

- Frequent changes in consumption schedules due to the requirements of agricultural technologies.

The main incentive for developing a mobile method based on renewable energy sources, which can ensure the energy independence of the consumer, is an increase in demand and a constant increase in prices and tariffs for centralized electricity and capacity. The local development of the mobile method based on renewable energy sources reduces the load from the distribution network, which helps to reduce electricity losses, introduces additional opportunities for the functioning of electricity markets, freeing up linear capacity [13].

The Tigray Agricultural Marketing Promotion Agency (TAMPA) launched in April 2014 in collaboration with the Sustainable Land Management Program (GIZ SLMP), promoting micro-and small-scale tomato processing enterprises using renewable energy sources. The target groups were cooperatives of farmers growing tomatoes in remote areas without access to electricity. The processing site can be built by farmers, as building materials are available on site or additionally provided by the GIZ SLM program [14].

Hybrid systems: Small-scale hybrid energy systems, also a mature technology, are used worldwide. By combining solar and wind power sources, hybrids can provide high availability of electricity without the need for a backup generator. These small hybrid systems are easy to transport and very easy to install; no special tools or concrete are required [15].

Autonomous power supply based on solar power plants with modern technical and economic parameters of photovoltaic converters is economically justified at a distance of at least $10 \mathrm{~km}$ from the power system and for mobile objects [16].

Using the above analysis results, we determine the estimated volumes of daily, seasonal, and annual required capacities for remote areas of fruit and vegetable farms. The calculations will be carried out for 280 hectares of remote farms in the Beruniy district. One of the energy-intensive agricultural techniques is considered irrigation and row-to-row processing.

Drip irrigation systems consist of low-power electrical equipment, are located far from each other in terms of electricity supply, and are seasonal in nature. Accordingly, the power supply networks of the regions where drip irrigation systems are used should be based on the integrated use of traditional and various types of renewable energy sources to design and develop energy supply systems.

These goals can be achieved with the help of modern methods of selecting the composition and parameters of autonomous and mobile solar-wind devices that can constantly provide electricity to small farms located far from centralized networks [5-6].

With the increase in the number of electric vehicles, the infrastructure for charging them should develop no less dynamically. Combined with the continuous improvement in battery life in electric vehicles, a tipping point in the mass opening of EV stations is about to come. As with other such innovative technologies, the transition to electric vehicles will gradually intensify [7].

With some delay, agricultural tractors will also be switched to electric drive, which directly affects the energy balance of local farms.

In addition to solar energy, the simplest hydroelectric power station can be used to provide mobile power supply to remote foothill areas from centralized networks, the construction of which is cheaper than all existing power plants per kilowatt of capacity. The 
garland micro electric power plant described in the article does not need a dam and can be installed on rivers with a depth of more than $25 \mathrm{~cm}$ at a flow rate above $1 \mathrm{~m} / \mathrm{s}$. A hybrid mobile power plant consisting of solar panels and a garland micro electric power plant with an average capacity of $6.6 \mathrm{~kW} * \mathrm{~h}$ (in the daytime) is in demand when implementing drip irrigation systems in foothill regions that do not have centralized power supply networks. [8].

For the mobile power supply organization, it is necessary to carry out appropriate calculations to determine the energy balance in the context of agrotechnical and production processes Figure 3.

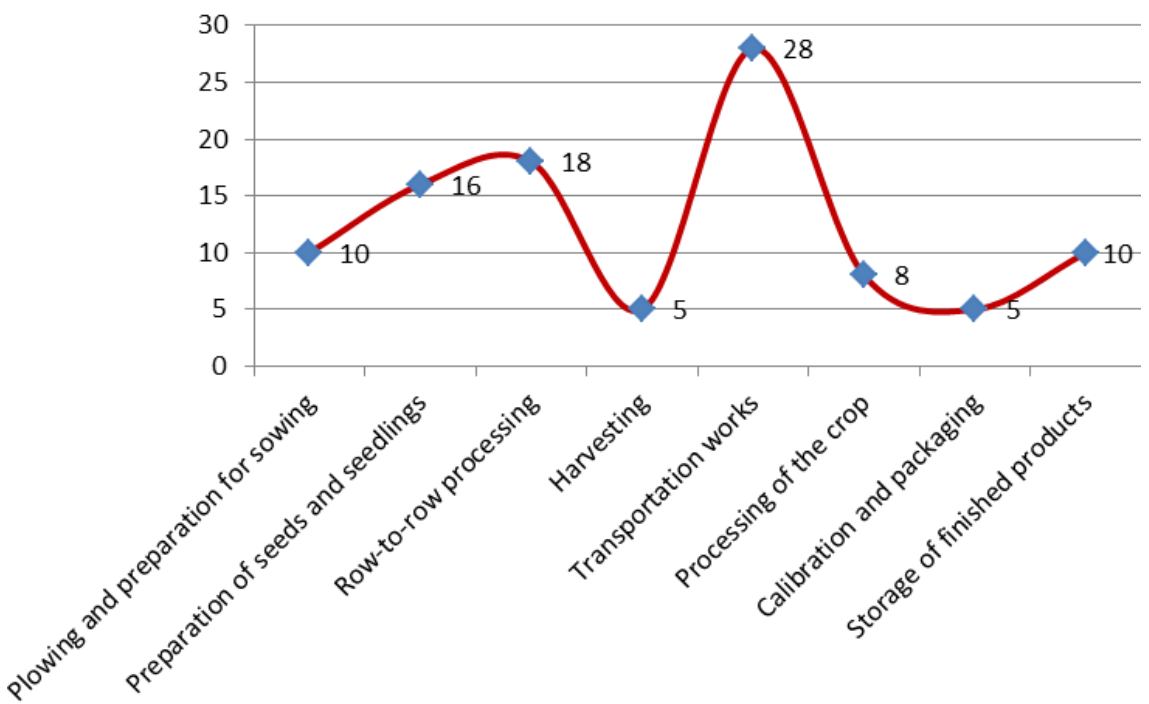

Fig. 3. Energy balance in the context of agrotechnical and production processes (on the example of fruit and vegetable growing)

The cost of electricity generated from the SFEU is still far higher than the cost of electricity generated by traditional power plants due to the high initial capital investment. Thus, the SPHERE should be used primarily to supply electricity to consumers (in particular, farms) that are remote from the existing power grids [17-21].

Of all the types of RES, the fastest growth (up to 50\% per year) is typical for the development of photo energy, despite the relatively high cost. At the current pace of development and the introduction of new technologies, the cost of electric solar systems by 2020. It will decrease by $2-3$ times.

\section{Conclusions}

A long-term plan for the diversification of electricity supply to agricultural consumers until 2030 has been developed based on the conducted research. 


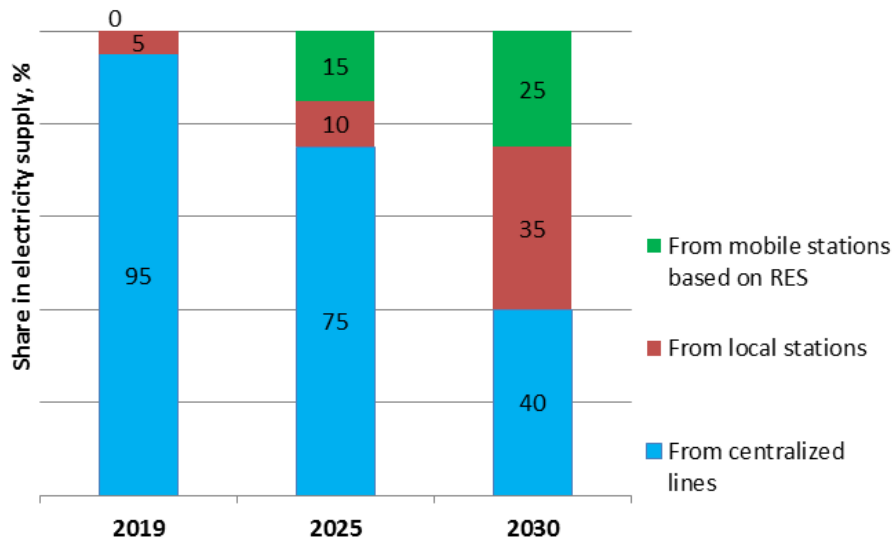

Fig. 4. Long-term plan for the diversification of electricity supply to agricultural consumers of the Beruniysky district until 2030

- To implement the above-mentioned diversification plan, it is necessary to develop a system of diversified electricity supply that includes centralized, local, and mobile energy sources;

- The system of diversified power supply of fruit and vegetable farms in the future leads to a reduction in the dependence of consumers on the centralized power supply;

- This, in turn, increases the level of reliability and efficiency of power supply, creates favorable conditions for the widespread introduction of modern resource-saving electrical technologies in the agricultural sector of the Republic of Uzbekistan.

\section{Acknowledgments}

The authors express their gratitude for the assistance provided in conducting experiments on the farm "Nuriev Madyar" and the technical staff of "Mir Solar" LLC for the preparation of a prototype mobile station.

\section{References}

1. Vinogradov A.V., Seifullin A. Yu. Analysis of the concepts of building power supply systems for rural consumers containing several sources of electrical energy // Bulletin of NGIEINo. 2 (105). S. 32-44. (2020).

2. Surkov M.A., Lukutin B.V., Sarsikeev E.Zh., Kiushkina V.R. World trends in the construction of autonomous power supply systems using renewable energy sources. Institute of Public Administration, Law and Innovative Technologies (IGUPIT). Online magazine "Science" No. 4. S. 2-15. (2012)

3. Akhmetshin A.T. Improving the efficiency of autonomous solar photovoltaic installations for power supply of agricultural consumers. Dissertation for the degree of candidate of technical sciences. Ufa..S. 172. (2016).

4. Tikhonov A.V. Improving the efficiency of combined systems of autonomous power supply based on renewable energy sources. Dissertation of the candidate of technical 
sciences: 05.14.08 / [Place of protection: Vseros. scientific research. in-t electrification sel. households] .- Moscow, 169 p. (2013).

5. Radjapov A., Bokiev A.A., Nuraliyeva N.A., Sultonov S.S. "Mobile power supply for drip irrigation systems" International Scientific Conference "Construction Mechanics, Hydraulics and Water Resources Engineering. CONMECHYDRO - 2020. IOP Conf. Series: Materials Science and Engineering 883 012109. IOP Publishing. doi:10.1088/1757-899X/883/1/012109. (2020).

6. Bokiyev.A.A., Nuraliyeva N.A., Sultonov S.S. Mobile source of energy based on renewable energy sources to improving irrigation systems. // International Journal of Advanced Research in Science, Engineering and Technology. Volume 7, Issue 11, ISSN: 2350-0328. - Pp. 3485-3491. November (2020).

7. Bokiyev.A.A., Botirov A.N., Toshmatov S.A. Prospects for conversion to electric drive of agricultural machinery in Uzbekistan. // International Journal of Advanced Research in Science, Engineering and Technology. Volume 7, Issue 11. ISSN: 23500328. - Pp. 3480-3484, November (2020).

8. Bokiev A.A., Sultonov S.S. "Mobile power supply based on solar panels and a garland micro hydroelectric power station for drip irrigation systems"// Scientific and technical journal of Namangan Institute of Engineering and Technology in the special issue of № 1 (volume 5, pages 316-323) (2020).

9. Bokiyev.A.A.,A.N. Botirov , N.A. Nuralieva. «Prospects of electrification of meliorative technical means in Uzbekistan»// Journal of "Sustainable Agriculture", //Tashkent, Tashkent Institute of Irrigation and Agricultural Mechanization Engineers. №2(3), pp - 27-29.(2019)

10. A. Radjabov, "Problems and prospects of the development of technology for the use of renewable energy in agriculture." Materials of the International conference "Prospects for the development of renewable energy sources in Uzbekistan", Tashkent. March 28-29, (2018).

11. A.A. Bokiev, N.A. Nuralieva. Prospects for transferring mobile technical equipment to electric drive in agriculture of the Republic of Uzbekistan. "Energy va resource tezhash muammolari", No. 3-4., 334-339 p. -Toshkent, (2018).

12. A. Sukhov, N. Stushkina, "Modernization of power supply systems for rural consumers through the introduction of distributed generation." Bulletin of the Russian State Agrarian University - Moscow Agricultural Academy named after KA Timiryazev, Electrification and automation of agriculture, No. 5; year. Moscow, p. 6973. [12a] (2018).

13. A.L.Kulikov, V.L.Osokin, B.V. Papkov. "Problems and Features of Distributed Power Industry". Bulletin of NGIEI. No. 11 (90) p. 12b. (2018).

14. Sheryazov Saken Koishybaevich "Methodology of rational combination of traditional and renewable energy resources in the system of energy supply to agricultural consumers." diss. 12c.

15. Rakhmonov S., Umurzakov U., Rakhmonov K., Bozarov I., Karamatov O. Land use and land cover change in Khorezm, Uzbekistan. E3S Web of Conferences, 227, 01002, (2021)

16. Tashimbetova MA, "Combined use of power plants based on renewable sources for power supply to local consumers" diss. Candidate of Technical Sciences: 05.14.08. Saint Petersburg, P. 134 12. (2005).

17. Voronin S.M. Formation of autonomous power supply systems for agricultural facilities based on renewable energy sources. diss. for the degree of Doctor of Technical Sciences. FGOU VPO "Azov-Black Sea State Academy" P. 12d. (2009). 
18. Umurzakov U., Mamatov F., Aldoshin N., Mirzaev B. Exploration of tillage technologies in the Republic of Uzbekistan, IOP Conference Series, Earth and Environmental Science, 614(1), 012168, (2020)

19. D.A. Kozyukov, B.K. Tsygankov, A.V. Bogdan. Development and research of photovoltaic installations for autonomous and backup power supply of farms. Theoretical and scientific-practical journal "Innovations in Agriculture" 5 (20)/ (FGBOU VPO KubSAU, Krasnodar, Russia). (2016).

20. Umurzakov U., and Djuraev B. Prediction of prices for agricultural products through markov chain model, International Journal of Psychosocial Rehabilitation, 24(3), pp. 293-303, (2020)

21. Umurzakov U., Mirzaev B., Salahodjaev R., Isaeva A., and Tosheva S. Energy consumption and economic growth: Evidence from post-communist countries. International Journal of Energy Economics and Policy, 10(6), pp. 59-65, (2020) 